A prototype axion detector in Daejeon, South Korea.

that symbolizes the country's ambition to become a world leader in basic research.

South Korea is spending heavily to achieve its goal. In 1999, the country's investment in research and development (R\&D) totalled $2.07 \%$ of its gross domestic product (GDP), just below the average for nations in the Organisation for Economic Co-operation and Development (OECD). In the latest figures, the country has stretched out a clear lead at the top. The $4.29 \%$ (63.7 trillion won, or US\$60.5 billion) that South Korea invested in R\&D in 2014 outstrips runner-up Israel (at $4.11 \%$ ), as well as regional competitor Japan and the United States. The biggest chunk of the money goes towards applied research and development in industry, but the government has made major investments in basic science, too.

The big hope is that the country can innovate its way out of a looming economic crisis - and win a Nobel prize in the process. South Korea aims to increase its investment to $5 \%$ of GDP by 2017, and last month, President Park Geun-hye's government announced that it would boost annual basic-science funding levels by $36 \%$ by 2018 , to 1.5 trillion won. "Basic research starts with intellectual curiosity among scientists and technicians, but it could be a source of new technologies and industries," Park said.

Can the country achieve its ambition? That depends who you ask. Some Korean scientists and policymakers doubt that it can sustain its high level of investment, and they worry that cultural barriers and bureaucracy are hindering research. Young scientists are voting with their feet: according to figures released in 2014 by the US National Science Foundation (NSF), nearly $70 \%$ of South Koreans who were awarded PhDs in the United States in 2008-11 planned to stay there.

Reorienting the nation's science focus is no easy task, says Youngah Park, president of the Korea Institute of S\&T Evaluation and Planning (KISTEP), a government think tank in Seoul. The country has long been an industryfocused 'fast follower' - excelling at quickly adopting technologies and products, such as semiconductors and smartphones, and making them better and cheaper. Now, Korea needs a new model, she says. "That is a very challenging and adventurous scheme for us."

\section{SHOCK AND AWE}

When the artificial-intelligence (AI) program AlphaGo beat Korean grandmaster Lee Sedol at the game Go this March, the impact on the national psyche was profound. The AlphaGo shock, as it came to be known, showed the country that AI was the future: Korea must catch up to the likes of Google DeepMind in London, which invented the Go-playing machine.

Within days, President Park announced that the government would invest 1 trillion won in
AI by 2020, and prod the private sector into investing a further 2.5 trillion won. The initiative's cornerstone would be a public-private research institute involving corporations such as Samsung and LG. But many scientists criticized the approach as a knee-jerk reaction that would funnel government money into product development, not into the type of basic research that the country needs.

The funding injection was typical of the strategy that has propelled South Korea's economy over the past few decades: the government set goals and then channelled money to corporate partners to carry them out. The formula was devised by Park's father, dictator Park Chung-hee, who seized power in a 1961

\section{"We have large funding and you can do what ever you want to."}

coup. During his 18-year reign, he favoured companies that grew into behemoths - conglomerates, called chaebol in Korea, such as Samsung, LG and Hyundai, which remain the backbone of the nation's economy today.

Powered by these industries, five decades of economic growth vaulted South Korea from developing-world poverty to membership of the group of 20 (G20) leading industrial nations. As the country moved painfully from dictatorship to democracy, government support for research remained a bipartisan priority - mainly as a driver for further growth. Korea's corporate giants still dominate the R\&D scene. According to KISTEP figures, of the 63.7 trillion won spent on R\&D in 2014, 49.2 trillion came from private enterprises. That includes more than half of the 11.2 trillion won spent on basic research. Much industrial research happens behind closed doors, although partnerships with academia are on the rise.

Meanwhile, government-funded labs also worked mainly towards developing industrial technologies, and blue-sky, basic research remained an afterthought. "Politicians don't distinguish between R\&D in technology and support in basic science," says physicist Doochul Kim. Until recently, he says, "there has been no support in basic science, basically".

Change arrived during the run-up to the 2007 presidential election, when a group of researchers pitched an idea to the nation's leading politicians: that the country build an Institute for Basic Science (IBS). The organization would be Korea's answer to Germany's academically elite Max Planck institutes and Japan's RIKEN centres. "It was the first time that scientists went forward and suggested their own big project for the nation," says Youngah Park, who was a legislator with the conservative party at the time. The institutes would be part of an even bigger plan to create a research and business megahub called the International Science and Business Belt - and this became government policy when conservative candidate Lee Myung-bak won the election.

Political wrangling subsequently forced the government to scale back some of its plans, but IBS survived, in modified form. Fifty IBS centres, one-third of them in Daejeon, would be funded at an average of 10 billion won a year each for at least 10 years - a boon for researchers, who would be offered secure support to pursue their ideas. "We have large funding and you can do whatever you want to," says Kim, now president of the IBS. Today, 26 of the centres have opened, with the rest hoped to follow by 2021 .

\section{AXION RACE}

The Center for Axion and Precision Physics (CAPP) at KAIST is one of them. Semertzidis became head of the centre in 2013, moving from Brookhaven National Laboratory (BNL) in Upton, New York.

In its quest to find the axion, CAPP is chasing a high-profile rival in the United States: the Axion Dark Matter Experiment (ADMX), based at the University of Washington in Seattle. "Very smart people, absolutely," Semertzidis says, with a disarming grin. "But we'll win, nonetheless - absolutely."

If axions are indeed part of dark matter, they should be all around us. CAPP's design - like that of the ADMX - uses a cavity that should resonate at the axion's mass, with strong magnets outside it that cause the particles to convert into two photons and pop into sight. But physicists don't know what the axion's mass is, so they have to scan for it, tuning the resonant frequency of the cavity with rods of copper or sapphire. It will take years for a single device to cover the whole range of possible frequencies.

CAPP has at least a year of development left, whereas ADMX is already beginning operations, giving it a significant head start. But CAPP plans to build not one, but seven cavities - all in that hole in the ground, down the hall. And it has more powerful magnets, developed at BNL. "We'll do it seven times better, because of the sheer power of money," says Semertzidis, who thinks that his team can leapfrog the ADMX within five years. ADMX leader Leslie Rosenberg suspects that it could, too. "CAPP is by far our most credible competitor," he says.

Whatever the outcome, Rosenberg says that CAPP's progress is a milestone for Korean physics. The country's willingness to spend landed foreign talent and technology. "These new IBS centres have moved them into the top tier," he says. The other 25 existing centres are pushing into fields ranging from gene editing to nanomaterials and pure mathematics. Roughly one-third of the IBS's budget 


\section{Science in South Korea}

Industrial research and development (R\&D) has long been a priority for South Korea as a driver of economic growth. In the past decade or so, more emphasis has been placed on basic research.

\section{R\&D investment}

South Korea's spending on R\&D has soared to more than $4 \%$ of its gross domestic product (GDP) - more than any other country in the world and double that of China and the European Union.

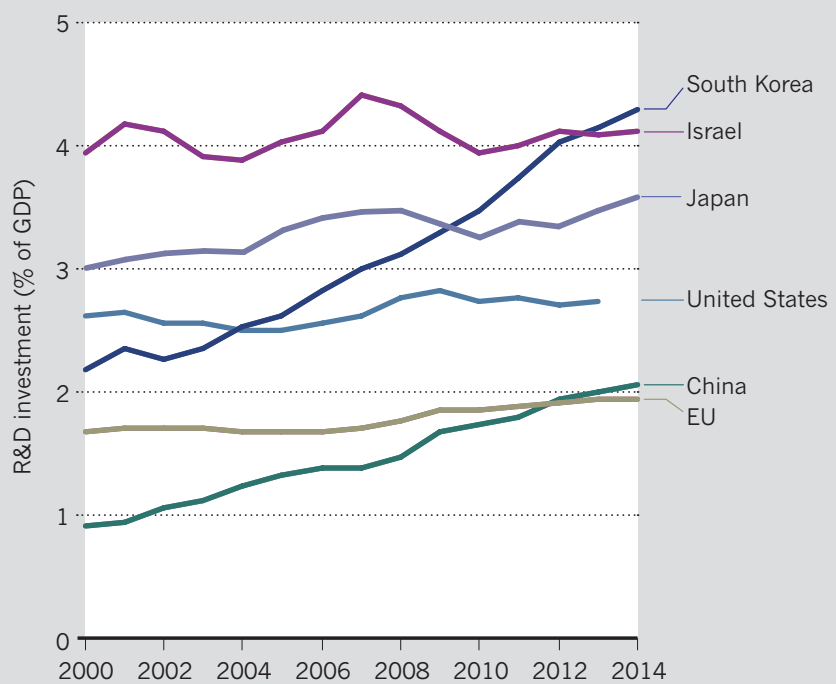

\section{Most R\&D money comes from industry ...}

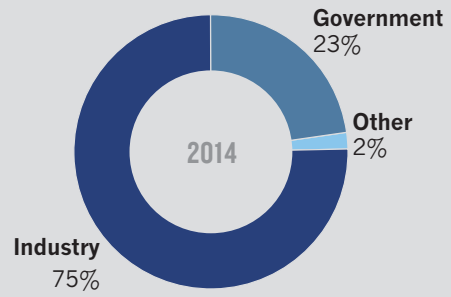

... and more goes to applied than to basic research.

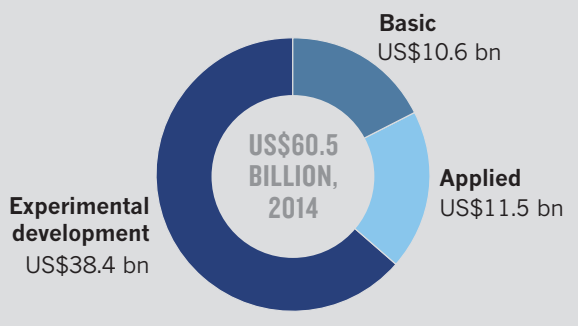

\section{Patents}

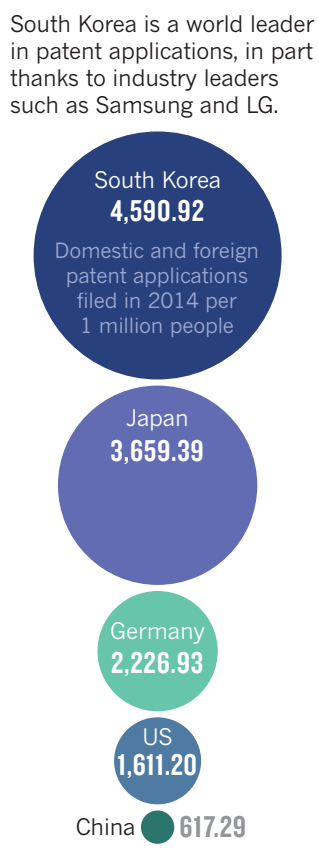

is devoted to one flagship effort - the Rare Isotope Science Project (RISP) in Daejeon, which seeks to build a heavy-ion accelerator for nuclear science and biomedical research.

South Korea is also investing in basicresearch facilities outside of IBS. The Pohang Accelerator Laboratory is receiving a 400-billion-won upgrade to house an X-ray free-electron laser that can image materials on nanometre and femtometre scales. And in 2014, the nation completed construction on a 107-billion-won, state-of-the-art Antarctic research centre in Terra Nova Bay, which quickly became the envy of the polarresearch community. "It was like a spaceship had landed," said US National Science Foundation polar-science head Kelly Falkner in 2014, months after attending the sleek facility's opening ceremony. "It's amazing to see what they can do by starting from scratch."

Rosenberg, for one, says that Korea is wise to invest in the IBS centres. "If they can continue to afford it, I think the pay-off is going to be enormous." And if they find the axion? "Oh my goodness, well, let's say it would instantly be a Nobel prize."

And that is something that this country wants very much indeed.

\section{NOBEL DREAMS}

Last October's Nobel-prize announcements triggered a wave of disappointment - again. There were no awards for South Korean researchers, but scientists in Japan, the nation's most bitter regional rival, collected shares in two: Satoshi Ōmura for developing a therapy for roundworm, and Takaaki Kajita for showing that neutrinos have mass. "Why no Korean Nobel laureates?" asked a headline in The Korea Times.

The question came up again at an oversight hearing of South Korea's parliamentary science committee, held that week. One member of parliament compared the full list of the two countries' Nobel laureates in science to a dismal football result: Japan 21, South Korea 0. "When will IBS score a goal?" he asked Kim.

\section{"Oh my goodness, well, let's say it would instantly be a Nobel prize."}

In some political quarters, IBS was originally hailed as a way to level the Nobel score, but Kim has pushed back against that, arguing that the 'Nobel complex' leads to shortsighted policies that chase hot topics and demand instant results. "We are only four years old," he told the committee. He noted that it took decades to develop the infrastructure at Japan's Kamiokande Observatory near Hida, where the neutrino breakthrough was made. "So you shouldn't ask that question," he said.

Korea did seem poised for a Nobel just over a decade ago, when stem-cell scientist
Woo Suk Hwang claimed to have derived the world's first stem-cell lines from cloned human embryos. But glory quickly turned to shame when Hwang was first found guilty of ethics violations in the way he collected women's eggs for research, and then discovered to have fabricated some of his work. The scandal left the impression that the country's oversight of research ethics and integrity was lax.

Scientists in Korea say that the scandal has brought about positive changes. Slowly, more Korean journals have begun to issue retractions, says Eric di Luccio, a structural biologist at Kyungpook National University in Daegu and many universities are using the plagiarismdetection site turnitin.com to check papers and theses. More attention is also being paid to bioethics, says Jin-Soo Kim, director of the IBS Center for Genome Engineering at Seoul National University. "Before the Hwang scandal, in the laboratory, people would just draw blood and do experiments," he says. "Now it's recognized that you shouldn't do it without approval" from an institutional review board.

But Kim says that one 'Hwang-gate' reform is now holding Korea back: in the wake of the scandal, the government enacted a ban on human-embryo research, with only occasional exceptions granted for stem-cell studies. Kim has been at the forefront of developments in CRISPR-Cas9 gene editing, a technique that is revolutionizing biomedical research, but he has found himself unable to use the technology for research in human embryos, even as teams in China, the United Kingdom and elsewhere forge ahead with such work. "It's a pity," says 


\section{Workforce}

South Korea has one of the world's highest proportions of researchers.

Researchers per thousand people in employment, 2013

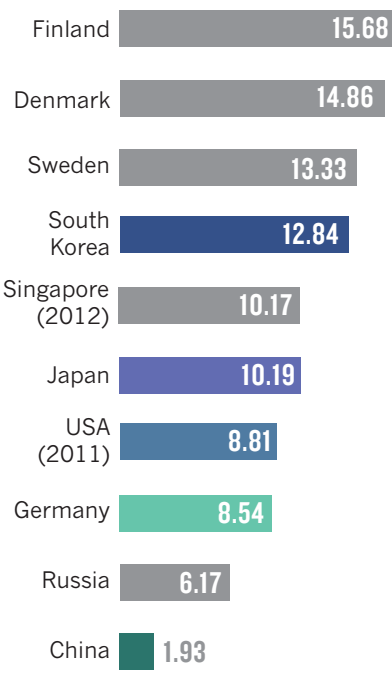

Kim, who has instead focused his efforts on engineering pigs and plants.

Researchers also chafe at other regulations. At public universities, tenure and promotion decisions are often based in part on evaluations that count papers by fractional contribution: a four-author paper, for example, would earn a scientist a small fraction of the credit of a single-author one. The system is "rather counterproductive", says di Luccio. It dissuades scientists from taking part in the large international collaborations of modern big-budget science, and encourages them to publish singleauthor papers in less-prestigious national journals to juice up their evaluation scores. "I did it three times already," he says. "This evaluation system is the exact opposite of what it should be to elevate scientific research." The government says that universities and other organizations are free to implement their own standards of evaluation and that nationally funded programmes use more qualitative measures. (IBS insulates researchers from paper counts.)

Some scientists see deeper problems with the academic culture, rooted in Korean society at large. Secondary and undergraduate education focus on test-taking and emphasize deference to teachers - tendencies that academics bemoan as discouraging the creativity and debate necessary in a lab. "When new students come, they are quiet - that is the Korean culture," says Jin-Soo Kim, who counters this by requiring his students to ask questions before they can leave group meetings.

Korean customs were a turn off for YoungIm Kim, who was doing a physics postdoc at
South Korea has more than doubled its academic publication output since 2005, overtaking similarly - but lagging behind its regional al Japan. Scientists publish most in chemistry, gineering, physics and life sciences.

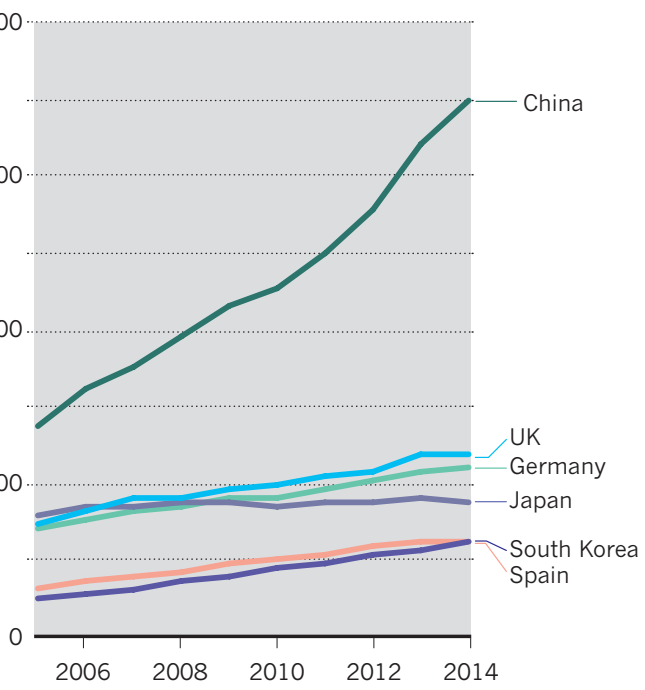

$-2008-2010-2012-2014$

the University of Oxford, UK, in 2014, when a friend sent her a link to a job posting at CAPP. Although she thrilled to the research, she was hesitant to return to her home country because of the hierarchical nature of Korean culture. "The only reason I applied is because of Yannis," she says. "If he were Korean, I wouldn't have." She is now a research fellow at CAPP.

Cultural barriers can have a disproportionate impact on female scientists. One example, says Young-Im Kim, is Korean drinking culture, in which men often stay out late with their male co-workers. Important workplace decisions are often made at such events, effectively excluding women. Such problems could go some way towards explaining why Korea has a wide gender gap in its scientific workforce. According to OECD figures, in 2010 less than $17 \%$ of researchers in South Korea were women. In Portugal, the OECD leader, the fraction is $45.5 \%$.

\section{STRETCHED RESOURCES}

Policy analysts warn that research spending may slow in the future, as Korea faces the likely prospect of an economic slowdown and, in the long term, a social-welfare net stretched to support an ageing population with one of the lowest birthrates in the world. And although R\&D expenditure continues to grow as a percentage of GDP (see 'Science in South Korea'), it is actually shrinking when viewed as a percentage of government spending, says Youngah Park. "That is a sign that we have no room to increase this government R\&D budget anymore."

Some critics say that spending is now too
Publications by discipline

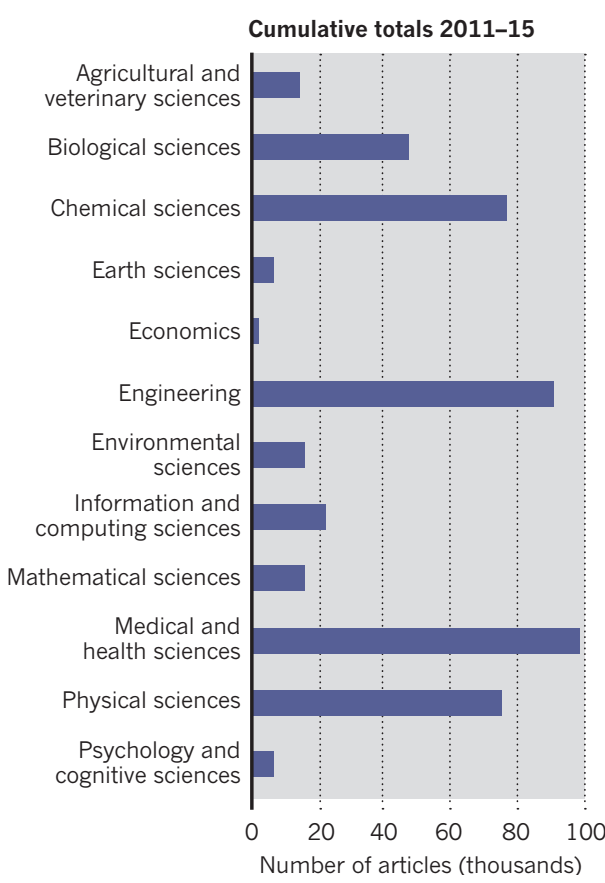

focused on IBS: that the bold plan is sucking up basic-research funds and reducing the pot of money available through other grants, creating a situation of haves and have-nots, and potentially quenching original - perhaps Nobel-worthy - projects. The shrinking grant pool is a legitimate issue, acknowledges Doochul Kim. But he thinks that the government should address it by shifting funds from applied research. It continues to subsidize such research when many say that it should be focusing on long-term basic research that industry wouldn't pursue.

"There is some excellent science done in Korea, but still, in general, the average is not as good as the advanced countries like the US, UK and Germany," says Jinwoo Cheon, director of the IBS Center for Nanomedicine at Yonsei University in Seoul. To spur investment in basic research, he adds, scientists have to convince the public and government officials of its intangible benefits. "Excellence in basic science is not easy to have, and it has to be rooted in our society - curiosity-driven research, and knowing different ways of thinking."

Sunchan Jeong, director of RISP, says that if there is such a thing as a recipe for winning a Nobel prize, then IBS has got it. "Select some competitive fields in the world and concentrate their investment on it. That's a good way." But there are no guarantees, he cautions: "The people in Korea should understand that scientific results are not necessarily repaid by some greater prize like the Nobel."

Mark Zastrow is a writer based in Seoul. 


\section{CORRECTION}

In the News Feature 'South Korea's Nobel dream' (Nature 534, 20-23; 2016), one

paragraph incorrectly gave numbers in billions instead of trillions of won. In fact, 63.7 trillion won was spent on R\&D, 49.2 trillion of which came from private enterprise; and 11.2 trillion won was spent on basic research. 